\title{
Intraoperative and perioperative complications in minimally invasive transforaminal lumbar interbody fusion: a review of 513 patients
}

\author{
Albert P. Wong, MD, ${ }^{1}$ Zachary A. Smith, MD, ${ }^{1}$ Alexander T. Nixon, MD, ${ }^{1}$ \\ Cort D. Lawton, MD, ${ }^{1}$ Nader S. Dahdaleh, MD, ${ }^{1}$ Ricky H. Wong, MD, ${ }^{2}$ Brenda Auffinger, MD, ${ }^{2}$ \\ Sandi Lam, MD, ${ }^{3}$ John K. Song, MD, ${ }^{4}$ John C. Liu, MD, ${ }^{5}$ Tyler R. Koski, MD, ${ }^{1}$ \\ and Richard G. Fessler, MD, PhD6 \\ 'Department of Neurological Surgery, Northwestern University; ${ }^{2}$ Section of Neurosurgery, University of Chicago, Illinois; \\ ${ }^{3}$ Department of Neurosurgery, Baylor College of Medicine, Houston, Texas; ${ }^{4}$ Section of Neurological Surgery, Advocate Illinois \\ Masonic, Chicago, Illinois; ${ }^{5}$ Department of Neurosurgery, University of Southern California, Los Angeles, California; and \\ ${ }^{6}$ Department of Neurosurgery, Rush University Medical Center, Chicago, Illinois
}

\begin{abstract}
OBJECT Transforaminal lumbar interbody fusion (TLIF) has become one of the preferred procedures for circumferential fusion in the lumbar spine. Over the last decade, advances in surgical techniques have enabled surgeons to perform the TLIF procedure through a minimally invasive approach (MI-TLIF). There are a few studies reported in the medical literature in which perioperative complication rates of MI-TLIF were evaluated; here, the authors present the largest cohort series to date. They analyzed intraoperative and perioperative complications in 513 consecutive MI-TLIF-treated patients with lumbar degenerative disc disease.
\end{abstract}

METHODS The authors performed a retrospective review of prospectively collected data on 513 consecutive patients treated over a 10-year period for lumbar degenerative disc disease using MI-TLIF. All patients undergoing either a first-time or revision 1- or 2-level MI-TLIF procedure were included in the study. Demographic, intraoperative, and perioperative data were collected and analyzed using bivariate analyses (Student t-test, analysis of variance, odds ratio, chi-square test) and multivariate analyses (logistic regression).

RESULTS A total of 513 patients underwent an MI-TLIF procedure, and the perioperative complication rate was $15.6 \%$. The incidence of durotomy was $5.1 \%$, and the medical and surgical infection rates were $1.4 \%$ and $0.2 \%$, respectively. A statistically significant increase in the infection rate was seen in revision MI-TLIF cases, and the same was found for the perioperative complication rate in multilevel MI-TLIF cases. Instrumentation failure occurred in $2.3 \%$ of the cases. After analysis, no statistically significant difference was seen in the rates of durotomy during revision and multilevel surgeries. There was no significant difference between the complication rates when stratified according to presenting diagnosis.

CONCLUSIONS To the authors' knowledge, this is the largest study of perioperative complications in MI-TLIF in the literature. A total of 513 patients underwent MI-TLIF (perioperative complication rate 15.6\%). The most common complication was a durotomy (5.1\%), and there was only 1 surgical wound infection $(0.2 \%)$. There were significantly more perioperative infections in revision MI-TLIF cases and more perioperative complications in multilevel MI-TLIF cases. The results of this study suggest that MI-TLIF has a similar or better perioperative complication profile than those documented in the literature for open-TLIF treatment of degenerative lumbar spine disease.

http://thejns.org/doi/abs/10.3171/2014.10.SPINE14129

KEY WORDS complications; durotomy; lumbar; minimally invasive; spine; transforaminal lumbar interbody fusion

ABBREVIATIONS ALIF = anterior lumbar interbody fusion; $A S D=$ adjacent-segment disease; $B M P=$ bone morphogenetic protein; CSF = cerebrospinal fluid; DVT = deep vein thrombosis; $\mathrm{EBL}=$ estimated blood loss; $\mathrm{MI}=$ minimally invasive; $\mathrm{PE}=$ pulmonary embolism; TLIF = transforaminal lumbar interbody fusion.

SUBMITTED February 12, 2014. ACCEPTED October 8, 2014.

INCLUDE WHEN CITING Published online February 20, 2015; DOI: 10.3171/2014.10.SPINE14129.

DISCLOSURE Dr. Fessler receives royalties from DePuy, Stryker, and Medtronic, but they are not related to minimally invasive techniques or technologies. The other authors report no conflict of interest concerning the materials or methods used in this study or the findings specified in this paper. 
$\mathrm{T}$ HE popularity of transforaminal lumbar interbody fusion (TLIF) has increased over the past decade. This surgical technique, pioneered by Harms and Rolinger $^{8}$ in 1982, was performed through a traditional midline incision with disruption of the "posterior tension band." It permitted posterior decompression and simultaneous 3-column arthrodesis for bony fusion. Compared with the midline posterior lumbar interbody fusion approach, the TLIF approach obviates the necessity for retraction of the thecal sac and nerve roots.

Of the studies that have evaluated complications of TLIF, most used the "open" surgical technique. ${ }^{18,19}$ Several authors evaluated the rate of perioperative complications using minimally invasive TLIF (MI-TLIF), but the studies were limited by small patient numbers., ${ }^{1,4,19,38}$ Reported complications included cerebrospinal fluid (CSF) leakage, nerve root injury, wound infection, screw breach, and migration of the interbody cage. This report comprises the largest study in the literature to analyze intraoperative and perioperative complications of MI-TLIF in more than 500 consecutively treated patients with lumbar degenerative disc disease.

\section{Methods \\ Data Collection}

A prospectively collected database of 513 consecutive patients treated by MI-TLIF for lumbar degenerative disease over a 10-year period, from January 2002 through October 2012, was retrospectively reviewed. The patients' data were collected from Northwestern University and the University of Chicago, from which institutional review board approval was obtained before conducting the study.

Included in the study were patients who had a 1- or 2-level MI-TLIF either as a revision or a first-time surgery. Diagnoses included spondylosis, spondylolisthesis, pseudarthrosis, adjacent-segment disease (ASD), spondylolysis, recurrent disc herniation, and previous failed surgery. Excluded patients included those who had had long-construct scoliosis correction, trauma, posterior lumbar interbody fusion, anterior lumbar interbody fusion (ALIF), extreme-lateral interbody fusion, direct lateral interbody fusion, combined procedures, open TLIF, tumor, or previous surgical infection.

Demographic data on these 513 patients were collected. Age, sex, preoperative diagnosis, level of fusion, multilevel fusion, and bone morphogenetic protein (BMP) use were noted. Intraoperative parameters included in the database were duration of operation, estimated blood loss (EBL), use of BMP, type of interbody cage, and screw-placement technique. Changes between preoperative and postoperative strength testing were noted, as were detailed lists of complications, subsequent surgeries, length of hospital stay, and disposition status at discharge (home vs inpatient rehabilitation). Statistical analyses were conducted using bivariate analysis (Student t-test, ANOVA, odds ratio, chisquare test) and multivariate analysis (logistic regression).

\section{Surgical Technique}

The MI-TLIF procedure includes bilateral paramedian incisions ( $3 \mathrm{~cm}$ in length), measured $4.5 \mathrm{~cm}$ lateral to the midline, localized over the disc space of the surgical level, as confirmed by intraoperative fluoroscopy and preoperative MRI. A K-wire is placed through the fascia onto the ipsilateral facet joint, followed by sequential muscle-splitting tubular dilators and the final expandable tubular retractor. Lateral fluoroscopy is used to confirm the correct surgical level, and the fiber-optic light source is attached to the retractor. The remainder of the surgery is performed with either loupes or a microscope. Monopolar electrocautery is used to dissect the soft tissue overlying the lamina and facet joint. A hemilaminotomy is performed with Kerrison rongeurs or a high-speed drill up to the rostral pedicle and down to the caudal pedicle. The residual facet joint may be removed with a combination of rongeurs, osteotomes, and a high-speed drill. Subsequently, the ligamentum flavum is resected to clearly expose the lateral edge of the thecal sac and the exiting and traversing nerve roots. Discectomy is performed in standard fashion, followed by placement of autograft or allograft ventral to the interbody cage. BMP may also be used, depending on patient risk factors and surgeon preference. The interbody cage is inserted under direct visual and fluoroscopic guidance to confirm its appropriate placement. Placement of the percutaneous pedicle screws is performed with fluoroscopic guidance or CT navigation. With fluoroscopy, Jamshidi needles are used to cannulate the pedicles using the so-called bull's-eye technique, followed by K-wire placement. A tap is used to "prep" the screw tract, and this is followed by placement of the percutaneous pedicle screws. Anteroposterior and lateral radiographs are used to confirm the proper placements and trajectories of the K-wires, tap screw, and pedicle screws. Rods and set screws are locked into position, and final radiography is performed. Standard closure consists of fascial and dermal sutures and a skin adhesive. Mean results are present$\mathrm{ed} \pm \mathrm{SD}$.

\section{Results}

\section{Patient Characteristics}

A total of 513 patients were treated with MI-TLIF performed by 4 neurosurgeons over a 10-year period, from 2002 to 2012, at two institutions. The mean age of the patients was $58 \pm 13.1$ years, and 299 of them $(58.3 \%)$ were female. Single-level fusions were performed in 432 patients $(84.2 \%)$, and multilevel fusions were performed in 81 patients $(15.8 \%)$; fusions were predominately at L4-5 and L5-S1 (Table 1). The MI-TLIF was a first-time surgery for 383 patients (74.7\%), and a revision operation in 130 patients $(25.3 \%)$. BMP was used in 480 patients $(93.6 \%)$. The majority of the preoperative diagnoses included spondylolisthesis, spondylosis, and spondylolysis (Table 1).

\section{Summary of Perioperative Data and Complications}

The overall mean operative duration was $228.9 \pm 75.8$ minutes. The mean EBL was $237.3 \pm 254.6 \mathrm{ml}$, and the mean length of stay in the hospital was $3.7 \pm 2.2$ days (Table 2). The operative parameter data were stratified according to single-level versus multilevel procedures (Table 3). Compared with patients who underwent a multilevel 
TABLE 1. Patient characteristics

\begin{tabular}{|c|c|}
\hline Parameter & Patient Data* \\
\hline Total no. of patients & $513(100)$ \\
\hline Age (yrs) & $58 \pm 13.1$ \\
\hline Sex (female) & $299(58.3)$ \\
\hline \multicolumn{2}{|l|}{ Preoperative diagnosis } \\
\hline Spondylolisthesis & $336(65.5)$ \\
\hline Spondylosis & $229(44.6)$ \\
\hline Spondylolysis & $25(4.9)$ \\
\hline Previous failed surgery & $16(3.1)$ \\
\hline ASD & $11(2.1)$ \\
\hline Recurrent disc herniation & $9(1.8)$ \\
\hline Pseudarthrosis & $1(0.2)$ \\
\hline \multicolumn{2}{|l|}{ Level of fusion } \\
\hline L4-5 & $272(53.0)$ \\
\hline L5-S1 & $133(25.9)$ \\
\hline L4-S1 & $51(9.9)$ \\
\hline L3-5 & $24(4.7)$ \\
\hline L3-4 & $21(4.1)$ \\
\hline Other & $12(2.3)$ \\
\hline \multicolumn{2}{|l|}{ Multilevel fusion } \\
\hline Yes & $81(15.8)$ \\
\hline No & $432(84.2)$ \\
\hline \multicolumn{2}{|l|}{ Revision surgery } \\
\hline Yes & $130(25.3)$ \\
\hline No & $383(74.7)$ \\
\hline \multicolumn{2}{|l|}{ BMP use } \\
\hline Yes & $480(93.6)$ \\
\hline No & $33(6.4)$ \\
\hline
\end{tabular}

* Data are number $(\%)$ of patients or mean \pm SD.

procedure, the patients who underwent a single-level procedure had a significantly shorter operative time $(\mathrm{p}<$ 0.01 ), a lower EBL ( $<0.01)$, and a similar length of hospital stay. The operative data were also stratified according to first-time versus revision procedures. There were no significant differences in operative times, EBL, or lengths of hospital stay between the 2 groups.

The majority of the patients $(n=433$ [84.4\%]) had an uncomplicated MI-TLIF (Table 4). Of the 80 patients with a reported complication, 54 patients (10.5\%) had 1 complication and 26 patients $(5.1 \%)$ had multiple complications (Table 4). Overall, there were 53 surgical complications $(10.3 \%)$ and 37 medical complications (7.2\%). The most common complication was durotomy (5.1\%) followed by

TABLE 2. Perioperative data

\begin{tabular}{lc}
\hline \multicolumn{1}{c}{ Parameter } & Mean \pm SD \\
\hline Operative time (mins) & $228.9 \pm 75.8$ \\
\hline EBL (ml) & $237.3 \pm 254.6$ \\
\hline Hospital stay (days) & $3.7 \pm 2.2$ \\
\hline
\end{tabular}

TABLE 3. Summary of perioperative data of patients who underwent single- versus multilevel and first-time versus revision MI-TLIF

\begin{tabular}{|c|c|c|c|c|}
\hline Variable & $\begin{array}{c}\text { No. of } \\
\text { Patients }\end{array}$ & $\begin{array}{l}\text { OR Time } \\
\text { (mins) }\end{array}$ & $\mathrm{EBL}(\mathrm{ml})$ & $\begin{array}{l}\text { Hospital } \\
\text { Stay (days) }\end{array}$ \\
\hline \multicolumn{5}{|l|}{ No. of levels } \\
\hline Single-level op & 428 & $213 \pm 3.0$ & $218.2 \pm 11.7$ & $3.6 \pm 0.1$ \\
\hline Multilevel op & 81 & $312.1 \pm 9.8$ & $343.5 \pm 32.5$ & $4.1 \pm 0.2$ \\
\hline$p$ value & & $<0.01$ & $<0.01$ & NS \\
\hline \multicolumn{5}{|l|}{ Surgery status } \\
\hline First-time op & 380 & $229.8 \pm 3.9$ & $237.7 \pm 13.5$ & $3.6 \pm 0.1$ \\
\hline Revision op & 129 & $226.8 \pm 6.7$ & $238.8 \pm 20.3$ & $3.8 \pm 0.3$ \\
\hline$p$ value & & NS & NS & NS \\
\hline
\end{tabular}

instrumentation failure (2.1\%) and postoperative urinary retention $(1.4 \%)$. There was only 1 case $(0.2 \%)$ of surgical wound infection. There was a statistically significant decrease in perioperative complications in patients who had a single-level MI-TLIF compared with those who had a multilevel MI-TLIF (OR 0.39 [95\% CI 0.71-0.95]; $\mathrm{p}=0.01)$. However, revision MI-TLIF was not associated with an increase in perioperative complications $(p=0.27)$. When the numbers of complications were stratified by presenting diagnosis, the data demonstrated no significant difference in the rates of perioperative complications according to presenting diagnosis $(\mathrm{p}>0.05)$ (Table 5).

\section{First-Time Surgery Compared With Revision Lumbar Surgery}

There were 130 patients $(25.3 \%)$ who had a previous lumbar surgery that required revision MI-TLIF and 383

TABLE 4. Complication subgroups

\begin{tabular}{cc}
\hline \multicolumn{1}{c}{ Complication } & No. (\%) of Patients \\
\hline Complications per patient & \\
\hline 0 & $433(84.4)$ \\
\hline 1 & $54(10.5)$ \\
\hline$>1$ & $26(5.1)$ \\
\hline Type of complication & $37(7.2)$ \\
\hline Medical & $53(10.3)$ \\
\hline Surgical & \\
\hline Complication subgroup & $26(5.1)$ \\
\hline Durotomy & $11(2.1)$ \\
\hline Instrumentation failure & $7(1.4)$ \\
\hline Urinary retention & $5(1.0)$ \\
\hline PE & $4(0.8)$ \\
\hline Neurological deficit & $4(0.8)$ \\
\hline lleus & $4(0.8)$ \\
\hline Hematoma & $2(0.4)$ \\
\hline DVT & $1(0.2)$ \\
\hline Wound infection &
\end{tabular}

DVT = deep venous thrombosis; $\mathrm{PE}=$ pulmonary embolism. 
TABLE 5. Complication rates stratified according to presenting diagnosis*

\begin{tabular}{lcc}
\hline \multicolumn{1}{c}{ Diagnosis } & $\begin{array}{c}\text { No. of } \\
\text { Patients }\end{array}$ & $\begin{array}{c}\text { No. (\%) of } \\
\text { Complications }\end{array}$ \\
\hline Spondylolisthesis & 336 & $56(16.7)$ \\
\hline Spondylosis & 229 & $32(14.0)$ \\
\hline Spondylolysis & 25 & $3(12.0)$ \\
\hline Previous failed surgery & 16 & $2(12.5)$ \\
\hline ASD & 11 & $4(36.4)$ \\
\hline Recurrent disc herniation & 9 & $0(0.0)$ \\
\hline Pseudarthrosis & 1 & $0(0.0)$ \\
\hline
\end{tabular}

* There were no significant differences between complication rates on the basis of diagnosis $(p>0.05)$.

patients (74.7\%) undergoing their first lumbar surgery. Overall, there were 26 perioperative complications in the revision-surgery group and 55 perioperative complications in the first-time-surgery group (OR 1.34 [95\% CI $0.80-2.24] ; \mathrm{p}=0.27)$. Eight patients $(6.2 \%)$ in the revision-surgery group and 18 patients $(4.7 \%)$ in the first-timelumbar-surgery group had a durotomy (OR 1.33 [95\% CI $0.56-3.13] ; \mathrm{p}=0.44)$. Five patients (3.8\%) in the revisionsurgery group and 3 patients $(0.8 \%)$ in the first-time-lumbar-surgery group had a perioperative infection (OR 5.06 [95\% CI 1.19-21.51]; $\mathrm{p}=0.02$ ).

\section{Single-Level Surgery Compared With Multilevel Surgery}

A total of 432 patients $(84.2 \%)$ underwent a single-level MI-TLIF and 81 patients $(15.8 \%)$ underwent a multilevel MI-TLIF. Overall, there were 58 perioperative complications in the single-level fusion group and 23 perioperative complications in the multilevel fusion group (OR 0.39 [95\% CI 0.71-0.95; $\mathrm{p}=0.01)$. Nineteen patients $(3.7 \%)$ in the single-level group and 7 patients $(1.36 \%)$ in the multilevel group had a durotomy (OR 0.48 [95\% CI 0.19-1.19]; $\mathrm{p}=0.48)$. Seven patients $(1.4 \%)$ in the single-level group and 1 patient $(0.2 \%)$ in the multilevel group had a perioperative infection (OR 1.31 [95\% CI 0.13-10.86]; $p=0.99$ ).

\section{Durotomy}

Twenty-six patients (5.1\%) had an intraoperative durotomy after MI-TLIF surgery. There were 19 cases $(4.4 \%)$ of durotomy with single-level fusions and 7 cases $(8.6 \%)$ with multilevel fusions. There were 18 cases $(4.7 \%)$ of durotomy with first-time surgeries and 8 cases $(6.2 \%)$ with revision surgeries. Neither multilevel fusions $(p=0.48)$ nor revision surgeries $(p=0.44)$ were significantly associated with an increased rate of durotomy. Eight durotomies (32.0\%) occurred during bony decompression, 8 (32.0\%) during the discectomy, 7 (28.0\%) during resection of the ligamentum flavum, and $2(8.0 \%)$ during cage insertion (Table 6). There was no significant difference between the rates of durotomy on the basis of the surgical step. Of the 26 patients with MI-TLIF complicated by a durotomy, each was treated with flat bed rest overnight, and none of the patients required intervention (lumbar drain, blood patch, or reoperation) for a CSF leak.
TABLE 6. Durotomy rates stratified according to surgical step*

\begin{tabular}{lc}
\hline \multicolumn{1}{c}{ Surgical Step } & No. of Cases $(\%)$ \\
\hline Bony decompression & $8(32.0)$ \\
\hline Discectomy & $8(32.0)$ \\
\hline Resection of ligamentum flavum & $7(28.0)$ \\
\hline Cage insertion & $2(8.0)$ \\
\hline Total & 25 \\
\hline
\end{tabular}

* There was no significant difference between the durotomy rates on the basis of surgical step $(p>0.05)$.

\section{Infection}

There was only 1 surgical wound infection $(0.2 \%)$, and it occurred after a first-time single-level fusion. Overall, there were 7 perioperative medical infections (1.4\%) with MI-TLIF surgery. The perioperative infections included pneumonia, Clostridium difficile diarrhea, cholecystitis, and urinary tract infection. All the medical infections occurred with multilevel fusions. There were 2 cases $(0.5 \%)$ of infection with first-time surgeries and 5 cases (3.8\%) with revision surgeries. The number of surgical levels in MI-TLIF was not associated with an increase in the number of perioperative infections $(p=0.99)$. However, there were statistically significantly fewer perioperative infections with first-time MI-TLIF compared with those with revision MI-TLIF (OR 5.06 [95\% CI 1.19-21.51]; $p=0.02$ ).

\section{Neurological Deficit}

Four patients $(0.8 \%)$ had new postoperative weakness after MI-TLIF surgery. All 4 of these patients had bilateral lower-extremity weakness that improved significantly with inpatient physical therapy. Two of the patients recovered to their baseline level of function. Two patients $(0.4 \%)$ had partial recovery but weakness after MI-TLIF.

\section{Wound Hematoma}

Four patients $(0.8 \%)$ had a postoperative wound hematoma after MI-TLIF surgery. None of these patients demonstrated clinically significant weakness. Their diagnosis was made with routine postoperative CT scanning. Three of these patients experienced continued radicular symptoms and elected to undergo reoperation for evacuation of the wound hematoma.

\section{Instrumentation Failure}

Eleven patients $(2.1 \%)$ experienced perioperative instrumentation failure after MI-TLIF surgery. Five patients $(0.97 \%)$ had cage migrations diagnosed by comparing the intraoperative radiographs to the postoperative radiographs (Fig. 1). Two of the patients with postoperative cage migrations required revision surgery, whereas the other 3 patients did not have any clinical or other radiographically revealed complications. Six patients $(1.2 \%)$ suffered an intraoperative fracture of the K-wire used for percutaneous placement of the pedicle screws. In 1 case, the fractured $\mathrm{K}$-wire was retained within the vertebral body and could not be retrieved; it resulted in no clinical significance (Fig. 2). In 5 of the cases, the K-wire was retrieved and resulted 


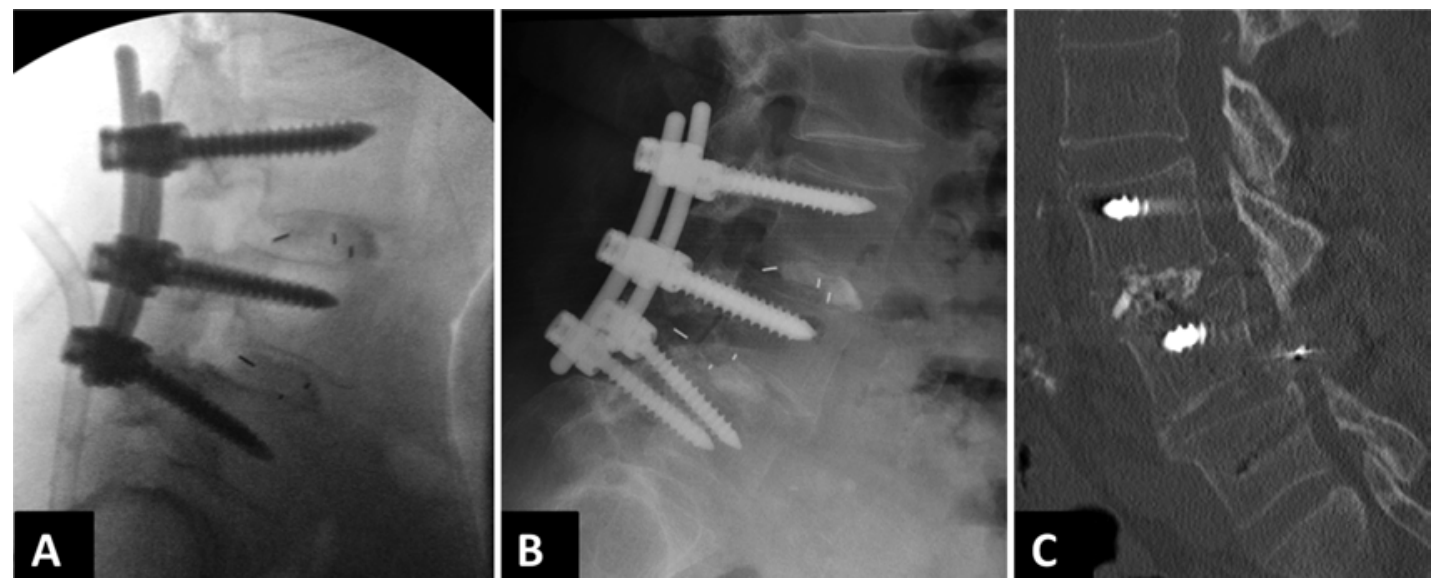

FIG. 1. A: Intraoperative lateral radiograph shows appropriate positioning of the pedicle screws, rods, and interbody cages. B: Follow-up lateral radiograph 6 weeks later shows posterior migration of the L4-5 interbody cage. C: Sagittal CT image of the lumbar spine confirms the posterior migration of the L4-5 interbody cage, which necessitated revision surgery.

in no further clinical significance. In 1 case, a fractured K-wire that had migrated ventral to the vertebral body (Fig. 3) required intraoperative repositioning with a minimally invasive direct lateral transpsoas approach and safe removal of the K-wire fragment. None of the 6 patients with K-wire fractures suffered any long-term clinical consequence from the instrumentation failure.

\section{Thromboembolism}

Seven patients $(1.4 \%)$ had either a deep vein thrombosis (DVT) or pulmonary embolism (PE) after MI-TLIF surgery. Two patients $(0.4 \%)$ had a DVT, and 5 patients $(1.0 \%)$ had a PE; all 7 of these patients were treated with appropriate anticoagulation therapy. One of the patients $(0.2 \%)$ had a massive PE that resulted in cardiopulmonary instability and eventual death.

\section{Other Complications}

Seven patients $(1.4 \%)$ had transient postoperative urinary retention, and 4 patients $(0.8 \%)$ had transient postoperative ileus that eventually resolved without intervention. Three patients $(0.6 \%)$ had postoperative anemia, and 2 of these patients $(0.4 \%)$ required postoperative blood transfusions after an average intraoperative EBL of $425 \mathrm{ml}$.

\section{Complication Rate Based on Level of Surgeon Experience}

Complication rates based on each surgeon's experience level are listed in Table 7. Three of the 4 authors performed their first MI-TLIF during the study period. One author performed his first MI-TLIF before the study period in 2000. The surgeons' experience levels were stratified for each consecutive group of 15 cases. There were no significant differences between the groups when comparing their overall complication rates on the basis of the level of surgical experience $(\mathrm{p}>0.05)$.

\section{Discussion}

The traditional open TLIF is a well-established surgical approach, and the literature supports its efficacy, safety, and rate of perioperative complications. ${ }^{6,7,21,22,24,26,34,38}$ Tormenti et al. ${ }^{31}$ described the largest analysis of the openTLIF approach and associated perioperative complications. To our knowledge, we present here the largest MITLIF series to date of more than 500 consecutive patients
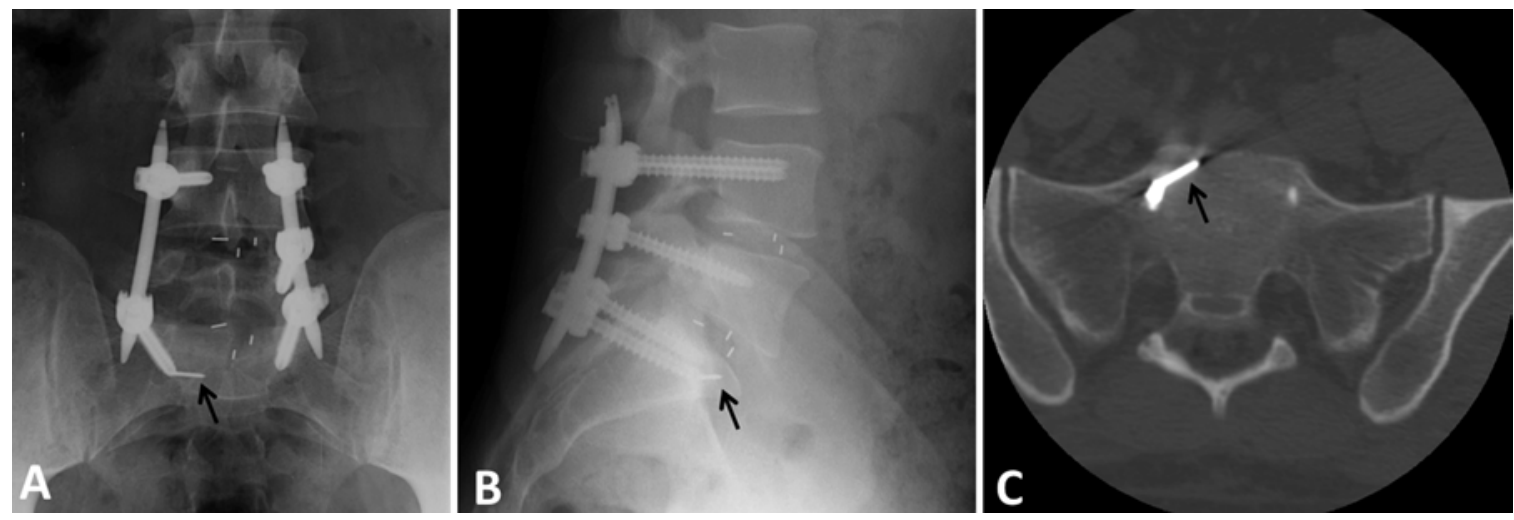

FIG. 2. Anteroposterior (A) and lateral (B) radiographs of the lumbar spine show the fractured K-wire confined within the body of the sacrum, and this K-wire fracture was confirmed by an intraoperative axial CT scan (C). The arrows mark the fractured K-wire tip. 


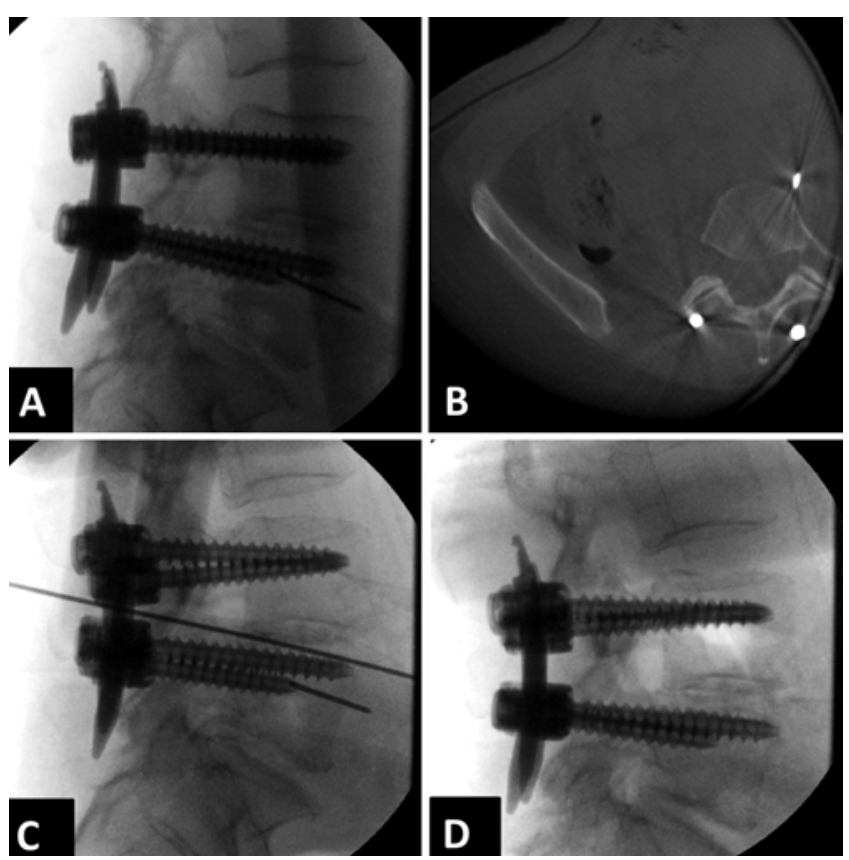

FIG. 3. A: Intraoperative lateral radiograph shows the fractured K-wire extending ventral to the vertebral body. B: An intraoperative axial CT scan confirmed that the fractured K-wire extended ventral to the $\mathrm{L} 5$ vertebral body. C: The patient was repositioned in the lateral decubitus position, and a K-wire was used to localize the surgical level for a direct lateral approach. D: Final intraoperative radiograph shows removal of the K-wire fragment.

who underwent MI-TLIF for lumbar degenerative disc disease and characterize the perioperative complications. We compare the MI-TLIF intraoperative and perioperative complication profiles with the established data on open TLIF in the literature. At our institution MI-TLIF had an overall low perioperative surgical and medical complication rate of $15.6 \%$. The complication subgroups compare favorably with those of open TLIF: intraoperative durotomy $(5.1 \%)$, hardware failure $(2.3 \%)$, infection $(0.2 \%)$, neurological deficit $(0.8 \%)$, wound hematoma $(0.8 \%)$, medical complications, thromboembolic event (1.4\%), urinary retention (1.4\%), and ileus (1.8\%). These comparisons are discussed in more detail in the next sections.

\section{Complication Types and Rates \\ Durotomy}

A review of open-TLIF studies suggests a durotomy incidence of 0\%-20\% (average 4.6\%). ${ }^{6,7,21,22,24,26,34}$ Reported results from MI-TLIF studies suggest a durotomy incidence of $0 \%-12.9 \%$ (average 2.9\%). ${ }^{2-4,10,13,15,17,28,36-40}$ The overall rate of durotomy was $5.1 \%$, which is similar to the rates of durotomy in MI-TLIF and open TLIF reported in the literature. ${ }^{2-4,10,13,17,28,36,37,38,40}$ The rates of durotomy were higher with multilevel fusions than with single-level fusions ( $8.6 \%$ vs $4.4 \%$, respectively) and higher with revision than with first-time surgeries (6.2\% vs $4.7 \%$, respectively) but did not reach statistical significance.

In our study, the majority of the durotomies occurred when using Kerrison rongeurs during 1 of 3 specific steps:
TABLE 7. Complication rates stratified according to surgeons' experience level*

\begin{tabular}{|c|c|c|c|c|c|}
\hline \multirow[b]{2}{*}{$\begin{array}{c}\text { Surgeon } \\
\text { No. }\end{array}$} & \multicolumn{5}{|c|}{ Complication Rate (\%) for Surgeons Who Have Performed } \\
\hline & $\begin{array}{c}1-15 \\
\text { Surgeries }\end{array}$ & $\begin{array}{c}16-30 \\
\text { Surgeries }\end{array}$ & $\begin{array}{c}31-45 \\
\text { Surgeries }\end{array}$ & $\begin{array}{c}46-60 \\
\text { Surgeries }\end{array}$ & $\begin{array}{c}>60 \\
\text { Surgeries }\end{array}$ \\
\hline 1 & 6.7 & 20.0 & 0.0 & 0.0 & 12.4 \\
\hline 2 & 26.7 & 53.3 & 46.7 & 13.3 & \\
\hline 3 & 33.3 & 13.3 & 26.7 & 13.3 & 13.3 \\
\hline 4 & 26.7 & 13.3 & 6.7 & & \\
\hline
\end{tabular}

* There were no significant differences between the overall complication rates on the basis of level of experience $(p>0.05)$.

bony decompression, resection of the ligamentum flavum, or discectomy. Consequently, we recommend the following precautions to decrease the risk of a durotomy during an MI-TLIF. Before using a biting instrument such as a Kerrison rongeur, a definitive and safe plane should be developed between the bony elements or ligaments and the thecal sac. This can be safely accomplished with a blunt dissector (e.g., nerve hook or Woodson elevator). The "biting window" of a Kerrison rongeur should always be turned $180^{\circ}$ away from the thecal sac with gentle upward traction to avoid an inadvertent durotomy. Similarly, during a discectomy, the thecal sac and nerve roots should be clearly identified before incision or resection of the anulus fibrosus. A blunt dissector (e.g., bayoneted Penfield No. 4 instrument) may be used to identify and separate the thecal sac from the underlying discoligamentous complex. A right-angle dissector can then be used for dissection ventral to the thecal sac to confirm a safe plane above the anulus. If there is significant resistance with the right-angle dissector, the plane between the ventral thecal sac and anulus needs to be more clearly dissected or there may be dense scarring, which may increase the risk of a durotomy.

Traditionally, durotomies are closed with sutures and reinforced with a combination of patch grafts (muscle or fascia) and fibrin glue. One of the advantages of MI-TLIF over open approaches is the use of muscle-splitting tubular retractors, which minimizes the postoperative "surgical cavity" and helps tamponade against formation of a pseudomeningocele. Other authors have also described adequate durotomy repair in MI-TLIF with fibrin glue alone. ${ }^{3,38}$ For the majority of MI-TLIF cases with durotomies in our study, we placed a piece of Gelfoam or dural substitute on top of the durotomy site and sealed it with fibrin glue (DuraSeal; Covidien). Postoperatively, the patients were placed on flat bed rest overnight. It is an important observation that none of the patients in our study who underwent MI-TLIF and had a durotomy required postoperative intervention (blood patch, lumbar drain, or reoperation) for a CSF leak. We believe that this is a major advantage of the MI-TLIF procedure.

\section{Infection}

Perioperative infections are a significant source of morbidity in spine surgery. Wound infections may lead to discitis, osteomyelitis, meningitis, chronic hardware infection, revision surgery, accelerated degeneration of the 
infected level, or prolonged use of antibiotics and their associated adverse effects. A review of open-TLIF studies suggests a surgical-site infection rate of 0\%-9.2\%.6,24,26,38 A similar review of MI-TLIF studies suggests an infection rate of $0 \%-10 \% .^{12,14,17,20,23,29,35-37} \mathrm{O}$ 'Toole et al. ${ }^{16}$ found that the incidence of surgical wound infection was significantly lower after MI-TLIF (0.6\%) than after open TLIF (4.0\%); the decrease in the number of wound infections in that study was associated with a direct cost savings of $\$ 98,974$ per 100 MI-TLIF procedures performed..$^{8}$

In our study, there was 1 surgical wound infection $(0.2 \%)$, which compares favorably to other authors' experiences and may attest to the large volume and experience of the center. To decrease the rate of infection with MI-TLIF, we recommend avoiding placing fingers into the surgical wound, which may increase the risk of surgical wound infection if there are microscopic breaks in the surgeons' gloves. Seven perioperative medical infections (1.3\%) (including urinary tract infection and pneumonia) were observed in our study. Revision MI-TLIF had a higher rate of perioperative infections in our study than did first-time MI-TLIF, which accounts for all of these infections.

\section{Neurological Deficit}

The MI-TLIF approach enables aggressive discectomy and an increased lateral angle for interbody cage placement with minimal retraction of the thecal sac or nerve roots. In the literature, the incidence of postoperative neurological deficit in patients treated by open TLIF is $1 \%-$ $3 \% .5,25,31$ The incidence of neurological deficit in patients after MI-TLIF is reported to be $0.7 \%-9.5 \% .^{2-4,33,36,38,40}$ The neurological deficits reported in the literature are usually transient and often related to malpositioned hardware.

In our study, 4 patients $(0.8 \%)$ had new postoperative weakness after an MI-TLIF surgery; 2 of these instances were transient. In all 4 cases, the neurological deficit appeared as a concurrent loss of neurophysiological monitoring signals that occurred during placement of the interbody cage. To decrease the risk of neurological injury during placement of the MI-TLIF interbody cage, meticulous dissection and mobilization of the thecal sac and exiting and traversing nerve roots is essential. Once the thecal sac and associated traversing nerve root are mobilized, they can be protected medially with a nerve root retractor. Similarly, the exiting nerve root should be clearly defined. A Penfield No. 4 instrument placed caudal to the exiting nerve root may be used to protect against the pathway of the interbody cage. During placement of the interbody cage, the surgeon should avoid "overstuffing" the disc space. An oversized interbody cage may directly injure the nerve roots during placement or may cause a postoperative radiculopathy from indirect stretching of the nerve roots. In Grade 2 spondylolisthesis, the risk of injury to the traversing nerve root overlying the disc space is increased. In this scenario, careful mobilization of the nerve root with contralateral distraction will decrease the risk of neurological injury during the discectomy. In cases of high-grade spondylolisthesis (Grade 3 or above), we recommend avoiding complete reduction of the slippage, because it may lead to an increased risk of nerve injury. The incidence of neurological deficit was significantly lower in our study than those in the literature. This lower incidence may be a result of the consistent use of intraoperative neurophysiological monitoring during all spinal fusion procedures at our institution, which may report signal changes of impending injury to neurological elements. ${ }^{11}$

\section{Instrumentation Failure}

Instrumentation failure in spine surgeries can lead to pseudarthrosis of the construct and postoperative neurological deficits. A literature review of MI-TLIF complications secondary to instrumentation failure revealed that the most common etiology was related to pedicle screw placement (0\%-12.3\%). - $^{-4,13,27-30,32,33,35,36,40}$ Interbody graft migration after MI-TLIF has been reported to occur at a rate of $3.9 \%-5.8 \% .^{4,13,36,38}$ In our study, 11 patients $(2.1 \%)$ had perioperative instrumentation failure after an MITLIF surgery. Five patients $(0.97 \%)$ had cage migration, and 6 patients $(1.2 \%)$ suffered an intraoperative fracture of the K-wire used for percutaneous placement of the pedicle screws. For cases in which the fractured K-wire is retained within the vertebral body, the K-wire can be safely left in place (Fig. 2). Figure 3 illustrates a case in which a K-wire extended ventral to the vertebral body and a direct lateral approach was used to retrieve it. Three of the patients with cage migration required repositioning of the cage (Fig. 1). Several of the following steps may help minimize cage migration. Maximizing the dimensions of the interbody cage while the contralateral side is distracted will help prevent potential migration. The interbody cage trial should feel "snug" and difficult to remove without great effort. Once the interbody cage is safely positioned within the disc space, a flat or curved tamp may be used to "turn" the interbody cage within the disc space, which will alter the entrance and exit trajectory of the interbody cage and may reduce the likelihood of its migration. Finally, bilateral compression across the surgical levels will not only increase the likelihood of fusion but will also decrease the potential for cage migration.

Six patients suffered an intraoperative fracture of the K-wire used for guidance of the percutaneous pedicle screws. In the majority of these cases, the K-wire usually fractures at the tip because of the combination of overhead pressure from the tap or screw with excessive polyaxial movement resulting in bending and eventual fracture of the wire. To minimize the probability of a K-wire fracture, it is imperative to always maintain an "in-line" trajectory of the wire with the tap or screwdriver. Intraoperative visualization of the trajectory of the K-wire and knowledge of the surgical trajectory of the proposed pedicle screw are essential for maintaining proper alignment. In addition, intraoperative fluoroscopy with a lateral (rostrocaudal alignment) or anteroposterior (mediolateral alignment) radiograph can help identify whether the tap or screw is bending the $\mathrm{K}$-wire. An alternative method that may decrease the likelihood of a K-wire fracture is to place a Jamshidi needle through the pedicle and vertebral body first, which would dilate the cancellous channel, make the subsequent steps of tap and screw placement easier because of the decrease in transmitted force to the $\mathrm{K}$-wire tip, and therefore reduce the likelihood of a K-wire fracture.

In the majority of cases with K-wire fractures, the break 
occurs at the tip of the wire. The tip is usually difficult to retrieve, but it normally does not have any clinical significance (Fig. 2). Intraoperative radiography or CT scanning may clarify the position of the K-wire tip to be safely confined within the vertebral body. Subsequently, the pedicle screw should be left short of the fractured K-wire tip to prevent inadvertent migration of the tip ventral to the vertebral body. If this scenario occurs, the fractured tip ventral to the vertebral body may be retrieved through either a direct lateral interbody fusion or ALIF approach (Fig. 3). The anesthesiologist should carefully monitor the patient's blood pressure and heart rate for any suggestion of vascular injury. If there are any clinical concerns for vascular injury or if an ALIF approach is desired, we recommend obtaining an immediate intraoperative vascular surgery consultation.

\section{Limitations and Future Directions}

To our knowledge, this is the largest study to have evaluated intraoperative and perioperative results from a population of patients who underwent MI-TLIF surgery. However, the following limitations should be noted. Although all data were prospectively collected, the hypothesis-driven analysis was retrospective in nature and therefore limits the interpretation. We sought to evaluate the perioperative complications associated with elective single- or multilevel MI-TLIF. Consequently, specific patient populations (i.e., patients with trauma, infection, tumor, or scoliosis) were excluded from the study, and the data are more difficult to generalize to all patients. Finally, we evaluated only intraoperative and perioperative complications of MI-TLIF. Currently, the data on long-term functional and radiological outcomes are limited. Thus, future studies regarding the functional outcome and radiographic fusion rates of MI-TLIF would be significant contributions to the literature.

\section{Conclusions}

This report currently represents the largest study of perioperative complications in MI-TLIF in the literature. A total of 513 patients underwent MI-TLIF, and 80 total perioperative complications $(15.6 \%)$ occurred. The most common complication was durotomy $(5.1 \%)$, followed by instrumentation failure (2.3\%) and infection (1.4\%); only 1 case $(0.2 \%)$ was a surgical wound infection. There were statistically significantly more perioperative infections in patients who underwent revision MI-TLIF and more perioperative complications for those who underwent multilevel MI-TLIF cases. There was no statistically significant correlation between durotomy and revision surgery or multilevel fusion. None of the 26 patients with a durotomy from MI-TLIF required postoperative intervention. The results of this study suggest that MI-TLIF has a perioperative complication profile that is similar or to or better than that reported in the literature for open-TLIF treatment of degenerative lumbar spine disease.

\section{References}

1. Anand N, Hamilton JF, Perri B, Miraliakbar H, Goldstein T: Cantilever TLIF with structural allograft and RhBMP2 for correction and maintenance of segmental sagittal lordosis: long-term clinical, radiographic, and functional outcome. Spine (Phila Pa 1976) 31:E748-E753, 2006

2. Archavlis E, Carvi y Nievas M: Comparison of minimally invasive fusion and instrumentation versus open surgery for severe stenotic spondylolisthesis with high-grade facet joint osteoarthritis. Eur Spine J 22:1731-1740, 2013

3. Deutsch H, Musacchio MJ Jr: Minimally invasive transforaminal lumbar interbody fusion with unilateral pedicle screw fixation. Neurosurg Focus 20(3):E10, 2006

4. Dhall SS, Wang MY, Mummaneni PV: Clinical and radiographic comparison of mini-open transforaminal lumbar interbody fusion with open transforaminal lumbar interbody fusion in 42 patients with long-term follow-up. J Neurosurg Spine 9:560-565, 2008

5. Esses SI, Sachs BL, Dreyzin V: Complications associated with the technique of pedicle screw fixation. A selected survey of ABS members. Spine (Phila Pa 1976) 18:2231-2239, 1993

6. Faundez AA, Schwender JD, Safriel Y, Gilbert TJ, Mehbod AA, Denis F, et al: Clinical and radiological outcome of anterior-posterior fusion versus transforaminal lumbar interbody fusion for symptomatic disc degeneration: a retrospective comparative study of 133 patients. Eur Spine J 18:203-211, 2009

7. Goyal N, Wimberley DW, Hyatt A, Zeiller S, Vaccaro AR, Hilibrand AS, et al: Radiographic and clinical outcomes after instrumented reduction and transforaminal lumbar interbody fusion of mid and high-grade isthmic spondylolisthesis. J Spinal Disord Tech 22:321-327, 2009

8. Harms J, Rolinger H: [A one-stager procedure in operative treatment of spondylolistheses: dorsal traction-reposition and anterior fusion (author's transl).] Z Orthop Ihre Grenzgeb 120:343-347, 1982 (Ger)

9. Karikari IO, Isaacs RE: Minimally invasive transforaminal lumbar interbody fusion: a review of techniques and outcomes. Spine (Phila Pa 1976) 35 (26 Suppl):S294-S301, 2010

10. Kim JS, Kang BU, Lee SH, Jung B, Choi YG, Jeon SH, et al: Mini-transforaminal lumbar interbody fusion versus anterior lumbar interbody fusion augmented by percutaneous pedicle screw fixation: a comparison of surgical outcomes in adult low-grade isthmic spondylolisthesis. J Spinal Disord Tech 22:114-121, 2009

11. Lall RR, Lall RR, Hauptman JS, Munoz C, Cybulski GR, Koski T, et al: Intraoperative neurophysiological monitoring in spine surgery: indications, efficacy, and role of the preoperative checklist. Neurosurg Focus 33(5):E10, 2012

12. Lau D, Lee JG, Han SJ, Lu DC, Chou D: Complications and perioperative factors associated with learning the technique of minimally invasive transforaminal lumbar interbody fusion (TLIF). J Clin Neurosci 18:624-627, 2011

13. Lee KH, Yue WM, Yeo W, Soeharno H, Tan SB: Clinical and radiological outcomes of open versus minimally invasive transforaminal lumbar interbody fusion. Eur Spine J 21:2265-2270, 2012

14. McGirt MJ, Parker SL, Lerner J, Engelhart L, Knight T, Wang MY: Comparative analysis of perioperative surgical site infection after minimally invasive versus open posterior/ transforaminal lumbar interbody fusion: analysis of hospital billing and discharge data from 5170 patients. J Neurosurg Spine 14:771-778, 2011

15. McMahon P, Dididze M, Levi AD: Incidental durotomy after spinal surgery: a prospective study in an academic institution. J Neurosurg Spine 17:30-36, 2012

16. O’Toole JE, Eichholz KM, Fessler RG: Surgical site infection rates after minimally invasive spinal surgery. J Neurosurg Spine 11:471-476, 2009

17. Park Y, Ha JW, Lee YT, Oh HC, Yoo JH, Kim HB: Surgical 
outcomes of minimally invasive transforaminal lumbar interbody fusion for the treatment of spondylolisthesis and degenerative segmental instability. Asian Spine J 5:228-236, 2011

18. Parker SL, Adogwa O, Witham TF, Aaronson OS, Cheng J, McGirt MJ: Post-operative infection after minimally invasive versus open transforaminal lumbar interbody fusion (TLIF): literature review and cost analysis. Minim Invasive Neurosurg 54:33-37, 2011

19. Parker SL, Mendenhall SK, Shau DN, Zuckerman SL, Godil SS, Cheng JS, et al: minimally invasive versus open transforaminal lumbar interbody fusion for degenerative spondylolisthesis: comparative effectiveness and cost-utility analysis. World Neurosurg 82:230-238, 2014

20. Peng CW, Yue WM, Poh SY, Yeo W, Tan SB: Clinical and radiological outcomes of minimally invasive versus open transforaminal lumbar interbody fusion. Spine (Phila Pa 1976) 34:1385-1389, 2009

21. Potter BK, Freedman BA, Verwiebe EG, Hall JM, Polly DW Jr, Kuklo TR: Transforaminal lumbar interbody fusion: clinical and radiographic results and complications in 100 consecutive patients. J Spinal Disord Tech 18:337-346, 2005

22. Rihn JA, Patel R, Makda J, Hong J, Anderson DG, Vaccaro AR, et al: Complications associated with single-level transforaminal lumbar interbody fusion. Spine J 9:623-629, 2009

23. Rosen DS, Ferguson SD, Ogden AT, Huo D, Fessler RG: Obesity and self-reported outcome after minimally invasive lumbar spinal fusion surgery. Neurosurgery 63:956-960, 2008

24. Rosenberg WS, Mummaneni PV: Transforaminal lumbar interbody fusion: technique, complications, and early results. Neurosurgery 48:569-575, 2001

25. Roy-Camille R, Saillant G, Mazel C: Internal fixation of the lumbar spine with pedicle screw plating. Clin Orthop Relat Res (203):7-17, 1986

26. Salehi SA, Tawk R, Ganju A, LaMarca F, Liu JC, Ondra SL: Transforaminal lumbar interbody fusion: surgical technique and results in 24 patients. Neurosurgery 54:368-374, 2004

27. Schwender JD, Holly LT, Rouben DP, Foley KT: Minimally invasive transforaminal lumbar interbody fusion (TLIF): technical feasibility and initial results. J Spinal Disord Tech 18 Suppl:S1-S6, 2005

28. Selznick LA, Shamji MF, Isaacs RE: Minimally invasive interbody fusion for revision lumbar surgery: technical feasibility and safety. J Spinal Disord Tech 22:207-213, 2009

29. Shunwu F, Xing Z, Fengdong Z, Xiangqian F: Minimally invasive transforaminal lumbar interbody fusion for the treatment of degenerative lumbar diseases. Spine (Phila Pa 1976) 35:1615-1620, 2010

30. Smith ZA, Sugimoto K, Lawton CD, Fessler RG: incidence of lumbar spine pedicle breach after percutaneous screw fixation: a radiographic evaluation of 601 screws in 151 patients. J Spinal Disord Tech 27:358-363, 2014

31. Tormenti MJ, Maserati MB, Bonfield CM, Gerszten PC, Moossy JJ, Kanter AS, et al: Perioperative surgical complications of transforaminal lumbar interbody fusion: a singlecenter experience. J Neurosurg Spine 16:44-50, 2012

32. Tsahtsarlis A, Wood M: Minimally invasive transforaminal lumbar interbody fusion and degenerative lumbar spine disease. Eur Spine J 21:2300-2305, 2012
33. Tsahtsarlis A, Wood M: Minimally invasive transforaminal lumbar interbody fusion and spondylolisthesis. J Clin Neurosci 19:858-861, 2012

34. Vargas-Soto HA, Mehbod A, Mullaney KJ, Dykes D, Schwender J, Transfeldt E, et al: Salvage procedures for pseudarthrosis after transforaminal lumbar interbody fusion (TLIF)-anterior-only versus anterior-posterior surgery: a clinical and radiological outcome study. J Surg Orthop Adv 18:200-204, 2009

35. Villavicencio AT, Burneikiene S, Bulsara KR, Thramann JJ: Perioperative complications in transforaminal lumbar interbody fusion versus anterior-posterior reconstruction for lumbar disc degeneration and instability. J Spinal Disord Tech 19:92-97, 2006

36. Villavicencio AT, Burneikiene S, Roeca CM, Nelson EL, Mason A: Minimally invasive versus open transforaminal lumbar interbody fusion. Surg Neurol Int 1:12, 2010

37. Wang J, Zhou Y, Feng Zhang Z, Qing Li C, Jie Zheng W, Liu $\mathrm{J}$ : Comparison of clinical outcome in overweight or obese patients after minimally invasive versus open transforaminal lumbar interbody fusion. J Spinal Disord Tech 27:202-206, 2014

38. Wang J, Zhou Y, Zhang ZF, Li CQ, Zheng WJ, Liu J:

Comparison of one-level minimally invasive and open transforaminal lumbar interbody fusion in degenerative and isthmic spondylolisthesis grades 1 and 2. Eur Spine J 19:17801784,2010

39. Wong AP, Shih P, Smith TR, Slimack NP, Dahdaleh NS, Aoun SG, et al: Comparison of symptomatic cerebral spinal fluid leak between patients undergoing minimally invasive versus open lumbar foraminotomy, discectomy, or laminectomy. World Neurosurg 81:634-640, 2014,

40. Wu WJ, Liang Y, Zhang XK, Cao P, Zheng T: Complications and clinical outcomes of minimally invasive transforaminal lumbar interbody fusion for the treatment of one- or two-level degenerative disc diseases of the lumbar spine in patients older than 65 years. Chin Med J (Engl) 125:2505-2510, 2012

\section{Author Contributions}

Conception and design: Fessler, Lam. Acquisition of data: AP Wong, Nixon, Lawton, Auffinger, Song, Liu, Koski. Analysis and interpretation of data: Fessler, AP Wong, Lawton, Dahdaleh, RH Wong, Auffinger, Lam, Song, Liu, Koski. Drafting the article: AP Wong, Nixon, Lawton. Critically revising the article: AP Wong, Smith, Nixon, Lawton, Dahdaleh, RH Wong, Lam. Reviewed submitted version of manuscript: Fessler, AP Wong, Smith, Nixon, Lawton, Dahdaleh, RH Wong, Lam. Approved the final version of the manuscript on behalf of all authors: Fessler. Statistical analysis: Lam. Study supervision: Fessler, Smith, Dahdaleh.

\section{Correspondence}

Richard G. Fessler, Department of Neurosurgery, Rush University Medical Center, 1725 W. Harrison St., Ste. 855, Chicago, IL 60612. email: rfessler@rush.edu. 